\title{
ASPECTOS DA ANATOMIA FOLIAR DE ALGUMAS ESPÉCIES DE PAEPALANTHUS KUNTH, ERIOCAULACEAE DA SERRA DO CIPÓ (MINAS GERAIS)
}

Recebido em 09.05.94. Aceito em 20.07.95.

\author{
Neuza Maria de Castro ${ }^{1}$ \\ Nanuza Luiza de Menezes ${ }^{2}$
}

RESUMO: (Aspectos da anatomia foliar de algumas espécies de Paepalanthus Kunth, Eriocaulaceae da Serra do Cipó - Minas Gerais). O estudo da anatomia foliar das espécies de Paepalanthus Kunth.: P. bromelioides Silv.; P. macropodus Ruhl.; P. microphyllus (Giull.) Kunth; P. paulinus Ruhl.; P. robustus Silv.; P. scleranthus Ruhl. e P. speciosus (Bong.) Koer. mostrou uma semelhança no número e distribuição dos feixes vasculares. Em $P$. robustus e, menos marcadamente, em $P$. speciosus, estes feixes de tamanhos diferentes, encontram-se distribuídos em séries, com os feixes menores mais próximos da epiderme adaxial. As folhas revelam características xerofíticas em diferentes graus. Chama-se a atenção para a formação de feixes vasculares anfivasais no ápice das folhas.

Palavras chave: Eriocaulaceae; Paepalanthus; anatomia foliar; feixes anfivasais; bainha mestomática.

\begin{abstract}
Aspects of leaf anatomy of some species of Paepalanthus Kunth, Eriocaulaceae from Serra do Cipó - Minas Gerais). The anatomical studies in species of Paepalanthus Kunth: P. bromelioides Silv.; P. macropodus Ruhl.; P. microphyllus (Giull.) Kunth; P. paulinus Ruhl.; $P$. robustus Silv.; P. scleranthus Ruhl. and P. speciosus (Bong.) Koern., show similarity in the number and distribution of the vascular bundles. In $P$. robustus and, to a lesser extent, in $P$. speciosus, theses bundies of differing sizes occur in series, the smaller ones being closer to the adaxial epidermis. The leaves exhibit varying degrees of xeromorphy. Attention is drawn to the development of anphyvasal vascular bundles in the leaf apices.
\end{abstract}

Key words: Eriocaulaceae; Paepalanthus; leaf anatomy; amphyvasal vascular bundle; mestomatic sheath.

\footnotetext{
' Departamento de Biociências; Univerisdade Federal de Uberlândia, Caixa Postal 593 - 38405-382, Uberlândia, MG.

2 Departamento de Botânica; Instituto de Biociências, Universidade de São Paulo, Caixa Postal 11461 05422-970, São Paulo, SP.
} 


\section{Introdução}

A Serra do Cipó corresponde à porção da Cadeia do Espinhaço, localizada no município de Santana do Riacho (MG), com altitude média de $1.200 \mathrm{~m}$, temperatura média anual oscilando entre $18^{\circ}$ e $20^{\circ} \mathrm{C}$ (Moreira \& Camalier 1977). Nessa serra predominam, entre outros tipos de vegetação, os campos rupestres (Joly 1970).

Devido principalmente às características do substrato, as plantas dos campos rupestres estão sujeitas à pouca disponibilidade hídrica, mesmo na estação chuvosa, sendo comum observarem-se, nestas espécies, adaptações relacionadas não só à retenção de água, como também à sobrevivência em situações adversas extremas (Warming 1893, Joly 1970, Moreira \& Camalier 1977, Menezes 1984, Sajo \& Menezes 1986 e Giulietti et al. 1987).

Segundo Tomlinson (1969), as características anatômicas das Eriocaulaceae revelam uma tendência hidrofítica na família, com espécies aquáticas e anfíbias no gênero Eriocaulon. Entretanto, segundo o mesmo autor, inúmeras espécies, principalmente do gênero Paepalanthus, apresentam características xerofíticas.

Poucos são os estudos que interpretam ecologicamente as características estruturais apresentadas pela família. Entre estes citam-se: Monteiro et al. 1984 e 1985, Castro 1986, Castro \& Menezes 1990 e Scatena 1990.

O presente trabalho analisa a anatomia foliar de espécies do gênero Paepalanthus da Serra do Cipó (Minas Gerais), uma de cada secção, segundo o sistema de classificação proposto por Ruhland (1903). O gênero Paepalanthus foi o escolhido, pois além de ser o maior dentro da família é o melhor representado na Serra do Cipó.

\section{Materiais e métodos}

O material, proveniente da Serra do Cipó (Santana do Riacho - MG), foi coletado ao longo da estrada que liga Lagoa Santa a Conceição do Mato Dentro. As espécies analisadas foram: Paepalanthus bromelioides Silv. (CFSC 9068), Paepalanthus macropodus Ruhl. (CFSC 7393), Paepalanthus microphyllus (Giull) Kunth (CFSC 7274), Paepalanthus paulinus Ruhl. (CFSC: 7279), Paepalanthus robustus Silv. (CFSC 7338), Paepalanthus scleranthus Ruhl. (CFCS 7333) e Paepalanthus speciosus (Bong.) Koern. (CFSC 8486), cujas exsicatas encontram-se depositadas no Herbário do Departamento de Botânica do Instituto de Biociências da Universidade de São Paulo (SPF), como parte da Coleção da Serra do Cipó (CFSC).

As espécies foram escolhidas, não só por serem as mais representativas dentro de cada secção do gênero, mas também por mostrar variedade de hábitos e crescerem em diferentes habitats. A análise anatômica foi feita à partir de cortes histológicos obtidos à mão livre, em material fresco e/ou fixado em FAA 50 (Johansen 1940). Foram feitos cortes transversais e longitudinais das folhas, que posteriormente foram corados com verde-iodo-acético e vermelho-congo (Dop \& Gautie 1909). Para clarificação, usou-se a técnica de Simpson (1929) com o emprego de ácido acético à 75\%. 
A lignina foi identificada pelo emprego da solução de floroglucina e ácido clorídrico a 25\% (Johansen 1940) e a celulose, com o IKI e ácido sulfúrico a 75\%, do mesmo autor.

Os desenhos diagramáticos e em detalhe foram realizados através do uso do microscópio óptico, marca Zeiss, $\mathrm{N}^{\circ} 4716506$, dotado de câmara clara.

\section{Resultados}

As espécies de Paepalanthus analisadas exibem uma grande variedade de hábitos, desde plantas herbáceas diminutas como Paepalanthus scleranthus, com cerca de 1,5-2,0 cm de altura, até aquelas como $P$. speciosus, que chegam a atingir $2,0 \mathrm{~m}$.

Das espécies analisadas, apenas Paepalanthus macropodus vive em ambientes constantemente úmidos, crescendo às margens dos riachos. Todas as demais, crescem em ambientes secos, em terreno arenoso ou pedregoso. As folhas são sésseis e lanceoladas.

A seqüência das figuras 1-7 representam, respectivamente, diagramas de cortes transversais feitos na região mediana de folhas adultas de Paepalanthus bromelioides (Fig. 1), P. macropodus (Fig. 2), P. speciosus (Fig. 3), P. scleranthus (Fig. 4), P. paulinus (Fig. 5), P. microphyllus (Fig. 6) e P. robustus (Fig. 7). Observa-se uma semelhança no padrão anatômico das folhas que, basicamente, apresentam um grande número de feixes vasculares maiores e menores intercalados, exceto em $P$. scleranthus (Fig. 4) e P. microphyllus (Fig. 6), que possuem folhas muito reduzidas com um pequeno número de feixes. Nota-se ainda, que em $P$. robustus (Fig. 7), os feixes vasculares de diferentes tamanhos, encontram-se distribuídos em três séries, dispostas em diferentes níveis, os menores (setas) mais próximos da epiderme adaxial. Em $P$. speciosus (Fig. 3), tal característica também é observada, mas não de modo tão acentuado como em $P$. robustus.

Nas espécies estudadas, o clorênquima é descontínuo, pela presença das extensões das bainhas dos feixes vasculares (Fig. 1-7). Em algumas espécies, torna-se difícil distinguir a extensão de bainha do restante do parênquima aqǘfero, pois ambos os tecidos são formados pelos mesmos tipos de células (Fig. 1-3, 20, 22 e 36).

Geralmente, os feixes menores não apresentam tais extensões, ou então, apenas extensões em direção à epiderme adaxial (Fig. 2, 3 e 7). Em P. microphyllus (Fig. 6), nota-se apenas uma pequena extensão de bainha unindo o feixe mediano à epiderme abaxial.

As figuras 8 a 19 representam vistas frontais das epidermes (Fig. 8, 9, 11, 14 e 15), cortes transversais (Fig. 10, 12, 16 e 17) e longitudinais radiais (Fig. 13, 18 e 19), feitos no terço mediano da folha.

A epiderme foliar é sempre unisseriada (Fig. 10, 12, 13, 19, 20, 22, 25, 26, 28 e 30), no entanto, em P. robustus (Fig. 18, 31 e 33) e P. speciosus (Fig. 36) a epiderme adaxial se apresenta aparentemente bisseriada. 




2 

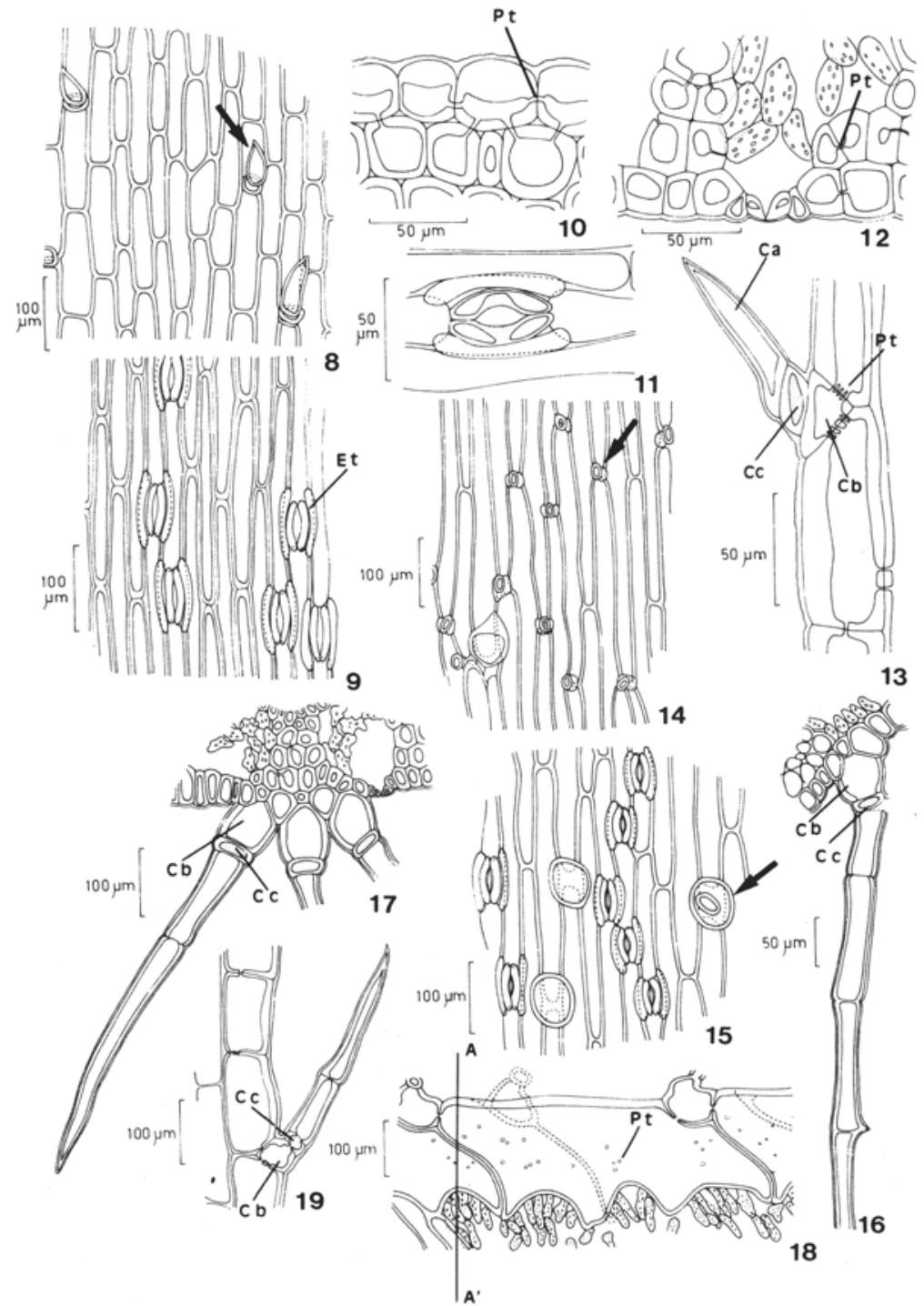

Figuras S-1Y. Puepalanthus bromelioides 8-13. Vista frontal da epiderme da face adaxial (8) e da face abaxial (9); detalhes da epiderme adaxial em corte transversal (10); do estômato em vista frontal (11); do estômato em corte transversal (12); do tricoma tector em corte longitudinal radial (13). Fig. 14-16 P. scleranthus - vista frontal da epiderme da face adaxial (14) e da face abaxial (15); detalhe de um tricoma tector (16). Fig. 17 P. speciosus .- detalhe de um grupo de tricomas tectores. Fig 18 P. robustus - detalhe da epiderme da face abaxial em corte longitudinal radial. Fig. 19P. microphyllus - detalhe de um tricoma tector em corte longitudinal radial. ( $C a$ - célula apical; $C b$ - célula basal; $C c$ célula colar; $E t$ - estômato; $P t$ - pontoação. - As setas indicam respectivamente um tricoma tector (Fig. 8) ou apenas a célula basal destes tricomas (Fig. 14 e 15) 
A epiderme da maioria das espécies estudadas, apresentam padrão semelhante ao visto em P. bromelioides (Fig. 8 e 9); P. microphyllus; apresenta padrão semelhante ao de $P$. scleranthus (Fig. 14 e 15). A epiderme em vista frontal, é formada por células alongadas no sentido longitudinal, e os estômatos com duas células subsidiárias, aparecem apenas na epiderme da face abaxial da folha (Fig. 9 e 15), formando fileiras longitudinais.

As figuras 11 e 12 representam em detalhe, respectivamente, a vista frontal e o corte transversal do aparelho estomático de $P$. bromelioides, onde se nota uma redução do lume na região mediana das células-guarda, devido a um intenso espessamento de suas paredes, aspecto este que se repete nas demais espécies.

Como se pode observar (Fig. 10, 12 e 17), as células epidérmicas apresentam paredes espessadas, com muitas pontoações (Pt) entre elas e entre as células epidérmicas e as células subepidérmicas.

É notável notar, que em $P$. robustus (Fig. 18) o tamanho das células da epiderme da superfície adaxial é muitas vezes maior do que as células do clorênquima abaixo.

Com exceção de P. bromelioides (Fig. 9), todas as espécies apresentam na face abaxial, entre as fileiras de estômatos, tricomas tectores, cuja célula basal pode ser vista na figura 15 (seta). Tricomas tectores, também estão presentes na epiderme adaxial em todas as espécies (Fig. 8 - seta). Geralmente, nas folhas adultas, restam apenas as suas cicatrizes (Fig. 14 - seta).

Os tricomas tectores são sempre filamentosos, unisseriados (Fig. 13, 16, 17 e 19) e ocorrem isolados ou em grupos (Fig. 17). P. robustus (Fig. 31) e P. speciosus (Fig. 36), apresentam grande número de tricomas na margem das folhas. Em $P$. bromelioides (Fig. 13) o tricoma é constituído por três células: uma célula basal (Cb) cônica, encaixada entre duas células epidérmicas, uma célula colar (Cc), na qual sempre se observa conteúdo (nesta e nas demais espécies analisadas), e uma única célula distal (Cd). Chama-se a atenção, para a presença de numerosas pontoações (Pt) entre a célula basal desses tricomas e as células epidérmicas vizinhas.

Os tricomas de P. paulinus (Fig. 19 e 26), P. scleranthus (Fig. 16 e 25), $P$. robustus (Fig. 31) e P. speciosus (Fig. 17 e 36), apresentam a célula basal (Cb) maior do que o observado nas demais espécies.

Em P. scleranthus (Fig. 16), P. speciosus (Fig. 17), P. paulinus (Fig. 19) e $P$. microphyllus (Fig. 30), a porção distal do tricoma é formada por duas ou mais células.

Em P. bromelioides (Fig. 20), P. macropodus (Fig. 22), P. paulinus (Fig. 28) e $P$. speciosus (Fig. 36), percebe-se uma camada subepidérmica composta por células desprovidas de clorofila, com paredes espessadas. Essa camada apresenta-se contínua sob a epiderme adaxial, enquanto que, sob a epiderme abaxial, é descontínua ao nível dos estômatos. A camada de células aclorofiladas e de paredes espessadas, mostra uma continuidade com as extensões de bainha que interrompem o mesofilo.

A margem da folha em P. bromelioides (Fig. 20) e P. macropodus (Fig. 22), é formada pela epiderme e por várias camadas de células aclorofiladas, e de paredes espessadas. Em P. paulinus (Fig. 26), nota-se apenas uma ou duas camadas de células de paredes espessadas, e nas demais espécies não se observa esta característica. 
O mesofiloé perfeita ou imperfeitamente isobilateral (Fig. 20, 22, 26, 28, 30, 31, 33 e 36), com uma ou duas camadas de parênquima paliçádico, seguida por várias camadas de parênquima esponjoso relativamente compacto e uma outra camada de parênquima paliçádico, às vezes não muito bem caracterizado. Faz exceção $P$. scleranthus (Fig. 25), que apresenta o mesofilo pouco diferenciado.

Entre os feixes vasculares observa-se o parênquima esponjoso formado por células, perfeita ou imperfeitamente braciformes (Fig. 20, 22, 25, 26, 28, 30, 31, 33 e $36)$.

Os feixes vasculares são colaterais, sendo os maiores envolvidos por uma bainha dupla, isto é, uma bainha externa (Be) e uma bainha interna (Bi). A bainha externa é de natureza parenquimática, cujas células apresentam paredes levemente espessadas e pontoadas (Fig. 21, 23, 32 e 34). A bainha interna (Bi) em P. bromelioides (Fig. 21), P. macropodus (Fig. 23), P. paulinus (Fig. 27) P. robustus (Fig. 32) e P. speciosus (Fig. 34), é formada por células de paredes espessadas, lignificadas e também pontoadas. Nos feixes menores, o espessamento das paredes das células é progressivamente menor, ou mesmo a bainha interna pode estar ausente em alguns pontos, com elementos do xilema e/ou do floema, tocando diretamente a bainha externa (Fig. 35).

Paepalanthus scleranthus (Fig. 25) e P. microphyllus (Fig. 30), apesar de possuírem duas bainhas envolvendo os feixes maiores, não apresentam a bainha interna lignificada. Nesses feixes, ela é, também, parenquimática e suas células possuem paredes ligeiramente mais espessadas do que as células da bainha externa.

Ainda com relação aos tecidos vasculares, chama-se a atenção para o fato de $P$. bromelioides (Fig. 21), P. microphyllus (Fig. 27) e P. speciosus (Fig. 34), apresentarem as células do floema $(\mathrm{Fl})$ com paredes espessadas, e em $P$. robustus (Fig. 32), para a presença de células de paredes espessadas (Ce), com afinidade pelo corante verdeiodo-acético, no interior do floema.

A seqüência de figuras 38-41 e 42-45 representam, respectivamente, em diagramas e detalhes, cortes transversais, feitos a partir da linha pontilhada (Fig. 37) em direção à região apical das folhas de $P$. paulinus. As seqüências de figuras 47-51 e 5254 , representam o mesmo para $P$. macropodus. A linha pontilhada na figura 46 , também indica o nível a partir do qual, os cortes foram realizados.

Em P. paulinus (Fig. 38-45), seguindo em direção ao ápice da folha, nota-se que os feixes vasculares colaterais (Fig. 38-1 e 42), vão se fundindo até se tornarem concêntricos (Fig. 41 e 45), ocorrendo também um considerável aumento no número de elementos de xilema (Fig. 43-45). Verifica-se ainda, uma redução progressiva no número de células de paredes espessadas e lignificadas da bainha interna (Bi), primeiro na região voltada para o xilema (Fig. 43), em seguida na região voltada para o floema (Fig. 44), até desaparecerem por completo (Fig. 45).

Paralelamente, os elementos de xilema, já em maior número, vão envolvendo o floema até circundá-lo completamente (Fig. 43-45), levando à formação de feixes vasculares anfivasais próximo ao ápice da folha, antes que se dê a fusão completa de todos os feixes no ápice (Fig. 41). Configuração semelhante foi observada, durante a fusão do feixes, em folhas de $P$. speciosus e $P$. robustus. 




Figuras 20-25. Cortes transversais e detalhes de feixes vasculares de: Paepalanthus bromelioides (20 e 21); P. macropodus (22 e 23) e de P. scleranthus (24 e 25). (Be - bainha externa do feixe; $B i$ - bainha interna do feixe; $\mathrm{Cb}$ - célula basal; $\mathrm{Et}$ - estômato; $\mathrm{Fl}$ - floema). 


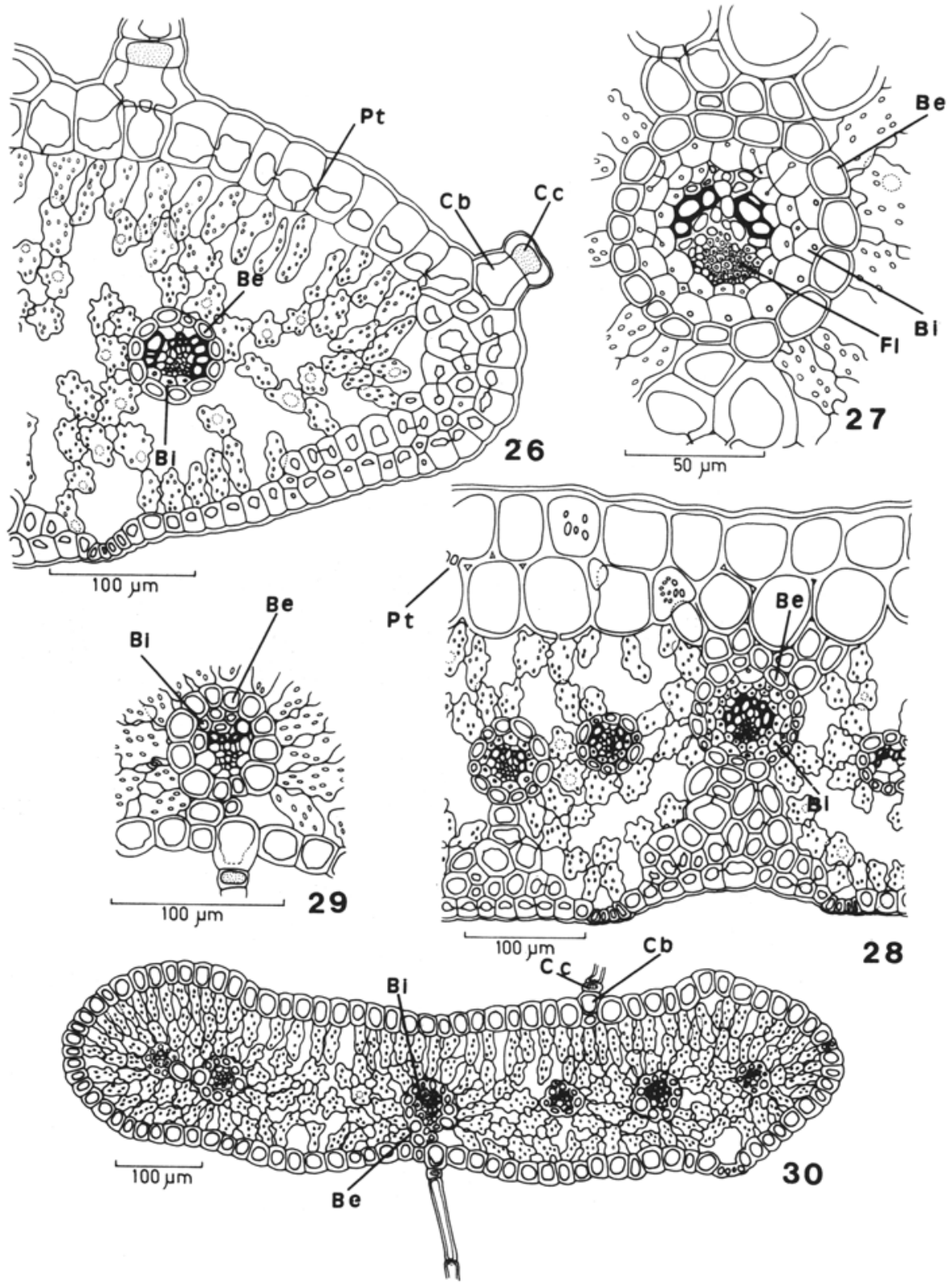

Figuras 26-30. Cortes transversais medianos do limbo e detalhes de feixes vasculares de : Paepalanthus paulinus (28-26) e $P$. microphyllus (29 e 30). ( $B e$ - bainha externa do feixe; $B i$ - bainha interna do feixe; $\mathrm{Cb}$ - célula basal; $\mathrm{Cc}$ - célula colar; $E t$ - estômato; $\mathrm{Fl}$ - floema). 

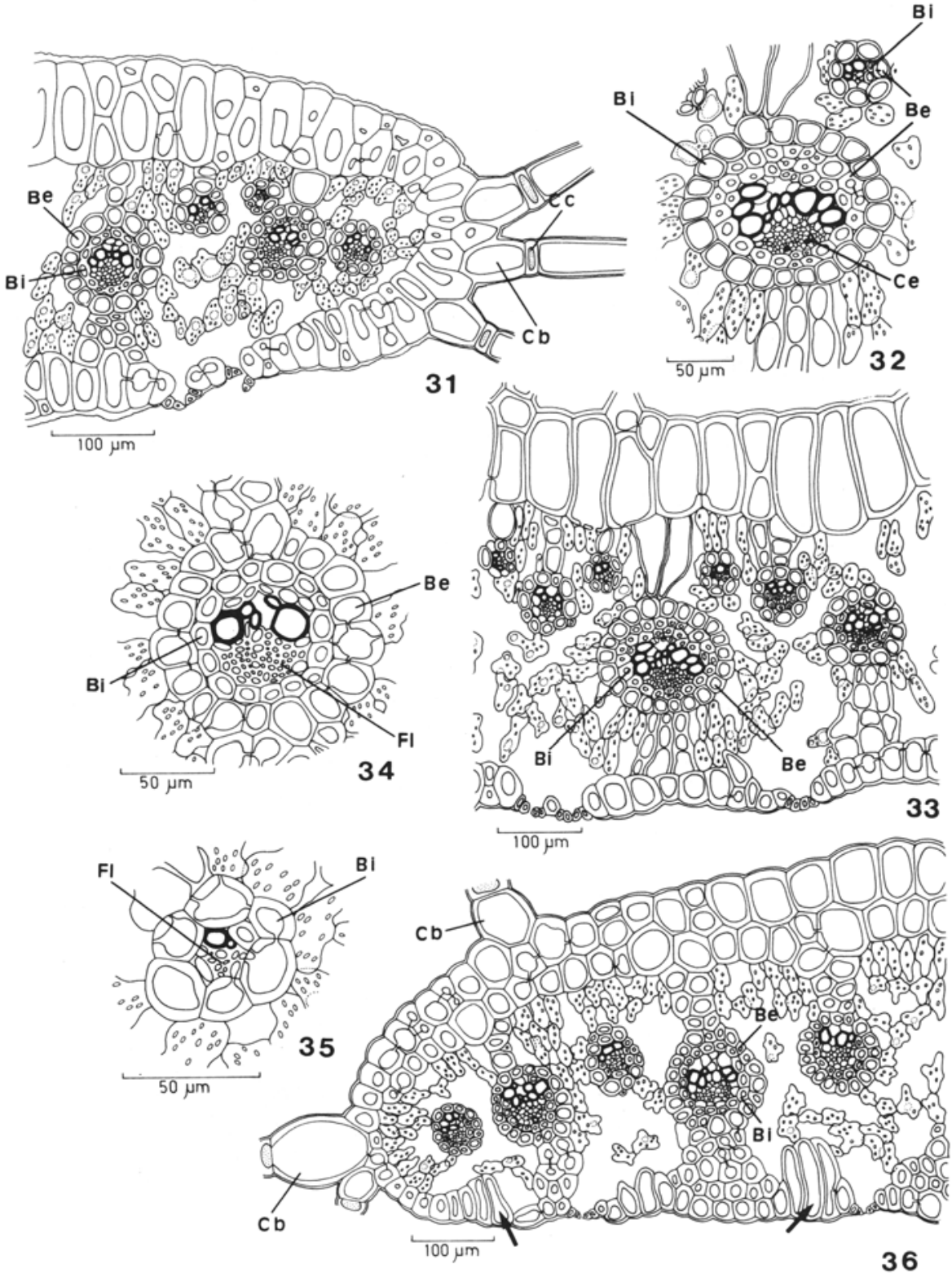

Figuras 31-36. Cortes transversais medianos e detalhes de feixes vasculares de Paepalanthus robustus (31-33) e $P$. speciosus (34-36). (Be - bainha externa do feixe; $\mathrm{Bi}$ - bainha interna do feixe; $\mathrm{Cb}$ - célula basal; $C c$ - célula colar; $E t$ - estômato; $F l$ - floema - As setas da figura 36 indicam as células altas da epiderme da face abaxial). 


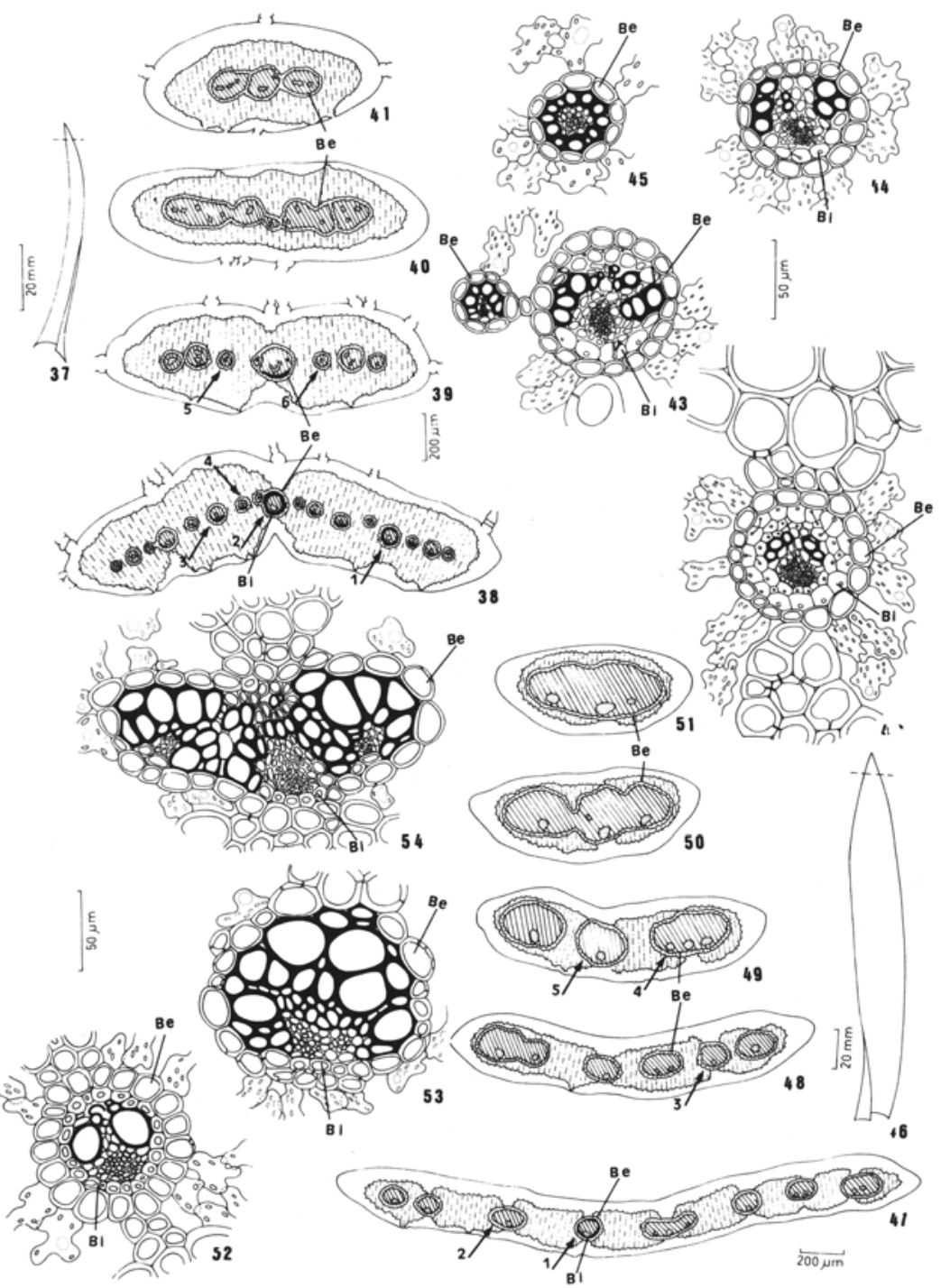

Figuras 37-54. Aspectos da estrutura foliar de Paepalanthus paulinus (Fig. 37-45) e de P. macropodus (Fig. 46-54). Fig. 38-41 - diagramas de cortes transversais efetuados a partir do nível indicado pela linha pontilhada na figura 37 , evidenciando a fusão dos feixes vasculares. Fig. 42-45 - detalhes dos feixes vasculares correspondentes, respectivamente, àqueles indicados pelas setas 1 e 2 (42), 3 e 4 (43), 5 (44) e 6 (45). Fig. 47-51 - diagramas de cortes transversais efetuados a partir do nível indicado pela linha pontilhada na figura 46, evidenciando a fusão dos feixes vasculares. Fig. 52-54 - detalhes dos feixes vasculares correspondentes, respectivamente, àqueles indicados pelas setas 1 (52), 2,3 ou $5(53)$ e $4(54)$. ( $B e$ - bainha externa do feixe; $B i$ - bainha interna do feixe). 
Em P. macropodus, a fusão dos feixes no ápice da folha acontece com algumas variações, como se observa na seqüência das figuras 47 a 54 . Os feixes vasculares colaterais (Fig. 52), à medida que se aproximam da região apical, também sofrem um considerável aumento no número de elementos do xilema, acompanhado da perda da bainha interna do feixe (Fig. 53). Nesta espécie, no entanto, observa-se uma forte tendência para a manutenção no arranjo colateral dos feixes (Fig. 47-51 e 52-54), antes que se dê a fusão completa dos mesmos, quando se pode observar que o xilema, acaba sempre por envolver o floema, apesar deste ainda ocupar uma posição excêntrica.

Paepalanthus bromelioides apresenta essa mesma tendência para a manutenção de feixes colaterais, durante a fusão dos mesmos, no ápice da folha.

\section{Discussão}

A presença de células epidérmicas com paredes espessadas e cutícula, comum às espécies estudadas, são aspectos notadamente xerofíticos, características estas, também, encontradas em folhas de outras plantas de campos rupestres, como em algumas espécies de Compositae (Handro et al. 1970, Sajo \& Menezes 1986), Velloziaceae (Menezes 1971, 1975 e 1984), Iridaceae (Chueri 1977), Leiothrix (Monteiro et al. 1985), Xyridaceae (Wanderley \& Cerati 1986, Sajo 1992 a,b) e Syngonanthus (Scatena 1990).

Segundo Pyyko (1966) características como essas, estão relacionadas com ambientes secos, podendo provavelmente proteger a planta contra a transpiração excessiva, além de funcionarem como suporte mecânico contra a ação dos ventos. De fato, as plantas mencionadas crescem nos campos rupestres, estando constantemente sujeitas à estresse hídrico, alta luminosidade e ventos excessivos.

Na epiderme das folhas são encontrados, com freqüência, tricomas com morfologia semelhante à verificada por Tomlinsom (1969), Giulietti (1978), Monteiro et al . (1984, 1985) e Scatena (1990), em espécies de outros gêneros de Eriocaulaceae.

A presença de tricomas nas folhas é uma característica frequente entre as espécies xerofíticas, sendo citada, também, para representantes de Compositae dos campos rupestres (Handro et al. 1970, Sajo 1982). Muitas funções têm sido atribuídas a estes tricomas, mas pouco se conhece sobre o seu real significado (Uphof 1962).

Conforme já estabelecido por Castro (1986) e Castro \& Menezes (1990), a existência de numerosas pontoações entre a célula basal dos tricomas e as células epidérmicas vizinhas, além da presença de conteúdo na célula colar em todos eles, sugerem que tais tricomas excerçam algum papel na passagem da água do meio para o mesofilo. Scatena (1990) propõe para Syngonanthus, que tais tricomas poderiam ser uma resposta ao estresse hídrico, possibilitando uma mobilidade maior da água para o interior da planta.

Os estômatos são do tipo paracítico e estão presentes apenas na epiderme da face abaxial, característica esta, segundo Parkhust (1978), mais comum em plantas de regiões úmidas do que secas. Através da análise das características foliares e auxiliado por pesquisas bibliográficas, investigações de herbário e modelos matemáticos, o 
autor chegou à conclusão de que, em regiões secas, a maior incidência é de folhas com estômatos situados nas duas faces.

Menezes (1984) estudando espécies de Velloziaceae, demonstrou que plantas crescendo numa mesma pedra, sob as mesmas condições de temperatura e umidade, podem apresentar estômatos restritos às fendas da superfície abaxial (no gênero Vellozia), ou em ambas as superfícies, no mesmo nível das demais células epidérmicas (no gênero Xerophyta e na subfamília Barbacenoideae). Segundo a autora, a presença de estômatos nas duas superfícies, representaria uma situação derivada, por estar relacionada à mecanismos fisiológicos de retenção de água, mais eficientes.

Por outro lado, os estômatos com duas células subsidiárias, o que parece ser uma característica comum às Eriocaulaceae (Tomlinson 1969; Giulietti 1978; Monteiro et al. 1984 e 1985; Castro 1986; Castro \& Menezes 1990 e Scatena 1990), segundo Stebbins \& Khush (1961), ocorre principalmente em plantas de ambientes úmidos. Portanto, o fato das Eriocaulaceae apresentarem estômatos, principalmente, na superfície abaxial e com apenas duas células subsidiárias, poderia representar uma situação em que a falta de água não fosse problema. Levando-se em conta que a maioria das espécies de Eriocaulaceae, são aquáticas ou estão ligadas à ambientes úmidos (Tomlinson 1969), talvez a falta de estômatos na epiderme da face adaxial esteja mais relacionada à proximidade filogenética com plantas aquáticas, do que à disponibilidade, ou não, de água.

Um aspecto notável, no que diz respeito à epiderme, é a presença de grupos de células mais altas que as demais, nas regiões intercostais da superfície abaxial, delimitando as câmaras subestomáticas, em Paepalanthus robustus e P. speciosus (Castro 1986 e Castro \& Menezes 1990). Segundo estas autoras, tais células parecem estar ligadas a uma proteção contra o colapso da câmara subestomática, no caso de estresse hídrico.

Em $P$. robustus (Fig. 31 e 33) e P. speciosus (Fig. 36), há uma aparente bisseriação da epiderme da face superior da folha. Na realidade, esta aparência, se deve ao fato dessas células epidérmicas serem extremamente longas, onde a extremidade de uma recobre parcialmente a célula subsequente. Assim, um corte que passe pela região indicada pela linha A-B (Fig. 18), nos dá uma falsa idéia de bisseriação, quando vista em corte transversal. Moebius (1887 apud Rosso 1966), sugeriu que as grandes células epidérmicas, alongadas verticalmente, por ele observadas em várias espécies de Orchidaceae, poderiam representar um tecido de reserva de água. O mesmo raciocínio pode ser aplicado para as células epidérmicas alongadas horizontalmente, observadas em $P$. robustus e $P$. speciosus.

Tomlinson (1969), separou as Eriocaulaceae em dois grupos, com base na organização do mesofilo: a) folhas com clorênquima restrito a faixas longitudinais, naquelas espécies que possuem extensões de bainha desenvolvidas; e b) folhas com clorênquima contínuo acima e abaixo dos feixes vasculares, nas espécies que não apresentam extensões de bainhas completas. As espécies de Paepalanthus estudadas, excetuando-se $P$. microphyllus, enquadram-se no primeiro grupo, pela presença de extensões de bainha em todas elas. 
Os feixes vasculares colaterais, aparecem arranjados em uma série única, eqüidistantes das epidermes, alternando-se feixes maiores e menores, exceto em $P$. robustus, e menos marcadamente em $P$. speciosus, nas quais se vêem três séries, dispostas em diferentes níveis, o que parece ser uma característica bastante incomum entre as Eriocaulaceae, sendo citada apenas para P. polyanthus (Tomlinson 1969), e para algumas espécies de Syngonanthus (Scatena 1990). Como P. polyanthus e $P$. robustus são espécies próximas taxonomicamente, pertencentes à mesma secção Actinocephalus, seria interessante a análise de um maior número de espécies deste e de táxons próximos, para observar se a disposição dos feixes vasculares na folha, seria ou não, uma boa característica a ser utilizada na taxonomia do grupo.

Possivelmente, a presença de feixes vasculares em mais de um nível, poderia representar uma concordância com a teoria do filódio de Arber (1925), segundo a qual, as folhas de Monocotiledonae, nada mais seriam do que um pecíolo achatado.

A presença de uma bainha dupla, envolvendo os feixes vasculares das folhas nas Eriocaulaceae é uma característica comum, referida por vários autores, entre eles: Holm (1901), Malmanche (1919), Tomlinson (1969), Giulietti (1978), Monteiro et al. (1984, 1985), Castro (1986), e Scatena (1990). Nas espécies de Paepalanthus analisadas, observou-se que os feixes maiores apresentam a bainha externa parenquimática, composta de células de paredes ligeiramente espessadas e pontoadas, e a bainha interna lignificada, formada por células de paredes fortemente espessadas e com muitas pontoações.

Os feixes progressivamente menores, vão apresentando menor espessamento e menor lignificação, nas paredes das células da bainha interna, até que esta deixe de existir, restando apenas a bainha externa, envolvendo os feixes de menor calibre. Em P. scleranthus e P. microphyllus as duas bainhas são parenquimáticas.

Embora diferentes autores tenham se referido à presença de uma bainha dupla, envolvendo os feixes vasculares das folhas de Eriocaulaceae, pouco é dito sobre a sua verdadeira identidade, Holm (1901) ressalta a semelhança da bainha interna dos feixes, com o mestoma das Gramineae.

Menezes $(1975,1984)$ ao estudar o deslocamento dos traços foliares no caule de Barbacenoideae, verificou que a bainha interna dos feixes das folhas, é representada pela própria endoderme lignificada e por analogia com as Gramineae, denominou-a bainha mestomática. Usando este mesmo raciocínio, Castro (1986), decidiu também empregar a denominação "bainha mestomática", à bainha interna dos feixes, visto que em todas as espécies analisadas, pareciam ser de natureza endodérmica.

Scatena (1990), estudando espécies de Syngonanthus, através de observações estruturais e homologia de tecidos, concluiu que em Syngonanthus, a bainha interna dos feixes vasculares das folha tem origem pericíclica e a bainha externa, origem endodérmica.

Este raciocínio poderia também ser válido para as espécies de Paepalanthus estudadas, tendo em vista a grande dificuldade de se comprovar a presença da endoderme, em cortes obtidos da região apical de caules destas plantas. No entanto, estudos ontogenéticos deveriam ser feitos para confirmar esta suposição. Além do 
mais, o fato de às vezes, a bainha interna apresentar mais de um extrato de células, pode representar mais uma evidência de que ela seria o periciclo e não uma endoderme. O fato desta bainha interna, ser mais ou menos espessada, lignificada ou não, depende apenas do grau de maturação do tecido e do porte da planta.

Nas folhas de Eriocaulaceae, a bainha externa dos feixes, geralmente, exibe extensões em direção às epidermes ou à hipoderme, o que pode ser verificado nos feixes de maior calibre em todas as espécies analisadas, exceto em P. microphyllus. As paredes celulares nestas extensões são intensamente espessadas e pontoadas, principalmente em $P$. bromelioides, $P$. paulinus, $P$. robustus e $P$. speciosus, mas em todos os casos analisados, não apresentaram reação positiva para lignina, com o uso de floroglucina e ácido clorídrico (Johansen 1940). Provavelmente, estas células apresentam paredes secundárias, no entanto, não se pode afirmar se lignificadas ou não, uma vez que o teste empregado para o reconhecimento da lignina, é considerado indicado apenas para o reconhecimento das ligninas que apresentam em seus grupos guaiacil terminações do tipo coniferaldeido (Lewis \& Yamamoto 1990).

As extensões de bainha costumam estar relacionadas com o transporte de água (Wylie 1943, 1947, 1949 e 1951 apud Monteiro et al. 1985). Essas extensões de bainha de dois feixes contíguos se comunicam, através de uma camada subepidérmica de células aclorofiladas e de paredes espessadas. Segundo Tomlinson (1969), nas Eriocaulaceae, essa camada de células representa uma hipoderme. Através de estudos de desenvolvimento das folhas de Syngonanthus, Scatena (1990) também verificou tratar-se de uma hipoderme. Admite-se que esta hipoderme, seja um tecido responsável não apenas por reserva de água, como também, pela movimentação da água no interior da folha.

Cortes transversais feitos na região apical das folhas de Paepalanthus, revelaram a presença de feixes anfivasais resultantes da fusão dos feixes colaterais, existentes nas porções mediana e basal do órgão.

Em Paepalanthus paulinus, $P$. robustus e $P$. speciosus os elementos do xilema, vão envolvendo o floema até circundá-lo completamente, originando assim feixes anfivasais.

A formação de feixes anfivasais na região apical das folhas, já havia sido descrito por Arber (1924) em Triglocin bulbosa L. e nos coleóptilos de certas Gramineae, em Paepalanthus por Castro (1986), em Xyris por Sajo (1989) e em Syngonanthus por Scatena (1990).

Cheadle \& Uhl (1948), em um trabalho sobre feixes vasculares em Monocotiledonae, consideram o tipo concêntrico anfivasal, como sendo o mais evoluído, embora não tenham constatado a presença deste tipo de feixe nas folhas das espécies por eles estudadas. As observações em Paepalanthus corroboram a idéia desses autores, no sentido de que feixes anfivasais sejam derivados, formados pela união de feixes colaterais.

Considerando-se os aspectos até aqui analisados para Paepalanthus, a tendência é supor que, ao contrário do estabelecido por Ruhland (1903), Hare (1950) e Tomlinson (1969), a direção evolutiva apresentada pelas Eriocaulaceae, talvez tenha 
sido da água para a terra; e que as espécies do gênero Paepalanthus, apresentam caracteres derivados. Essa suposição baseia-se na presença de feixes vasculares anfivasais nas folhas e a formação de complexos vasculares resultantes da fusão de traços foliares no caule de algumas das espécies de Paepalanthus, segundo observações de Castro (1986).

As espécies do gênero Paepalanthus, analisadas apresentam características xerofíticas em suas folhas, como por exemplo: epiderme formada por células de paredes espessadas e cuticularizadas, grande número de feixes vasculares e tecidos para armazenamento de água, além de caules subterrâneos desenvolvidos e com amido em seu parênquima (Castro 1986), características estas que as tornam melhor adaptadas às condições físicas encontradas nos campos rupestres.

\section{Referências bibliográficas}

Arber, A. 1924. Leaves of Triglocin. Bot. Gaz., 77: 50-62.

Arber, A. 1925. Monocotiledons - A morphological study: Cambridges University Press.

Castro, N. M. 1986. Estudos morfológicos dos órgãos vegetativos de espécies de Paepalanthus Kunth (Eriocaulaceae) da Serra do Cipó (Minas Gerais). Dissertação de Mestrado, Instituto de Biociências, Universidade de São Paulo.

Castro, N. M. \& MENEZES, N. L. 1990. Considerações sobre a natureza das células altas da epiderme abaxial das folhas de Paepalanthus Kunth - Eriocaulaceae. Bolm Botânica Univ. S. Paulo, 12: 95 100 .

Cheadle, V. I. \& UHL, N. W. 1948. Types of vascular bundles in de Monocotiledonae and their relation to the late metaxilem conducting elements. Amer. J. Bot., 35: 486-496.

Chueri, I. 1977. Anatomia das espécies do gênero Trimezia (Iridaceae) da Serra do Cipó. Dissertação de Mestrado, Instituto de Biociências, Universidade de São Paulo.

Dop, P. \& Gautie, A. 1909. Manuel de technique botanique, (Rudeval. F. R. ed./ Lamarre. J. ed.). Librairie Scientifique et Litteraire, Paris.

Giulietti, A. M. 1978. Os gêneros Eriocaulon L. e Leiothrix Ruhl. (Eriocaulaceae) da Serra do Cipó, Minas Gerais, Brasil. Tese de Doutorado, Instituto de Biociências da Universidade de São Paulo.

Giulietti, A. M.; Menezes, N. L.; Pirani, J. R.; Meguro, M. \& Wanderley, G. L. 1987. Flora da Serra do Cipó, Minas Gerais: Caracterização e lista das espécies. Bolm Botânica, Univ. S. Paulo 9: 1-152.

Handro, W.; Campos, J. F. B. M. \& Oliveira, Z. M. 1970. Sobre a anatomia foliar de algumas espécies de Compositae dos campos rupestres. Ciênc. Cul., 22: 107-126.

HarfE, L. C. 1950. The structure and development of Eriocaulon septangulare With. J. Linn. Soc. Bot., 53: $422-448$.

Holm, T. 1970. Eriocaulon decangulare L.. An anatomical study. Bot. Gaz., 31: 17-39.

Joly, A. B. 1970. Conheça a vegetação brasileira. São Paulo, EDUSP e Editora Polígono.

Johansen, D. A. 1940. Plant microtechnique. New York, Mc Graw-Hill Bood Co.

Lewis, N. G. \& Yamamoto E. 1990. Lignin: Ocurrence, Biogenesis and Biodegradation. Annu. Rev. Plant Plyysiol. Plant Mol. Biol. 41: 455-496.

Malmanche, L. A. 1919. Contribuition a l'etude anatomique des Eriocaulacées et des families voisines, Restiacées, Centrolepidacées, Xyridacées, Philydracées, Mayacacées. Tese. St. Clond.

Menezes, N. L. 1971. Traqueídes de transfusão no gênero Vellozia Vand.. Ciên. Cult., São Paulo, 23: 389422.

Menezes, N. L. 1975. Presença de traqueídes de transfusão e bainha mestomática em Barbacenoideae (Velloziaceae). Bolm Botânica, Univ. S. Paulo 3: 29-60 
Menezes, N. L. 1984. Características Anatômicas e Filogenia na Família Velloziaceae. Tese de Livre Docencia, Instituto de Biociências da Universidade de São Paulo.

Monteiro, W. R.; Giulietti,A. M. \& Castro M. M. 1984. Aspects of leaf structure of some species of Eriocaulon L. (Eriocaulaceae), from Serra do Cipó (Minas Gerais, Brasil). Revta. bras. Bot., 7(2): 137-147.

Monteiro, W.R.; Castro, M. M. \& Giulietti, A. M. 1985. Aspects of leaf structure of some species of Leiothrix Ruhl. (Eriocaulaceae) from the Serra do Cipó (Minas Gerais, Brasil). Revta. bras. Bot., 8: 109-125.

Moreira, A. A. N. \& Camalier, C. 1977. Relevo. In: Geografia do Brasil. Região Sudeste. Rio de Janeiro, IBGE, v. 3.

Parkhust, D. F. 1978. The adaptative significance of stomatal occurence on one of both surfaces of leaves. J. Ecol., London, 66: 367-383.

Pyykko, M. 1966. The leaf anatomy of East Patagonian xeromorphic plants. Ann. Bot. Fenn., 3: 453-622.

Rosso, S. W. 1966. The vegetative anatomy of the Cypripedioideae (Orchidaceae). J. Linn. Soc., London (Bot.), 59: 309-341.

Ruhland,W. 1903. Eriocaulaceae. In: Engler, A. Das Pflanzenreich. Weinheir. H. R. Engelmann, v. 13(IV-30).

Sajo, M. G. 1982. Estudos dos órgãos vegetativos de espécies de Vernonia Screb. (Compositae) da Serra do Cipó (Minas Gerais). Dissertação de Mestrado, Instituto de Biociências da Universidade de São Paulo.

Sajo, M. G. 1992a. Organização vascular do caule em Xyris L. (Xyridaceae). Bolm. Bot. Univ. S. Paulo 12: 49-66.

Sajo, M. G. 1992b. Estudos morfoanatômicos em órgãos foliares de Xyris L. (Xyridaceae). Bolm. Bot. Univ. S. Paulo 12: 67-86.

Sajo, M. G. \& Menezes, N. L. 1986. Anatomia do rizóforo de espécies de Vernonia Screb. (Compositae) da Serra do Cipó, MG. Revta. bras. Bot., 46(1): 189-196.

Scatena, V. L. 1990. Morfoanatomia de espécies de Syngonanthus Ruhl. (Eriocaulaceae) dos campos rupestres do Brasil. Tese de Doutorado, Instituto de Biociências da Universidade de São Paulo.

Simpson, J. L. 1929. A short method of chearing plant tissues for anatomical studies. Stain Technol., 4: 131-132.

Tomlinson, P. B. 1969. Commelinales - Zingiberales. In: METCALFE, C. R. Anatomy of the Monocotyledons. Oxford. At the Claredon Press, v. 3.

Uphof, J. C. T. 1962. Plant Hairs. In: Handbuch der Pflanzenatomie. Bd 4. T5 (K. Linsbauer, ed.), Bebr. Borntraeger, Berlin.

Wanderley, M. G. L. \& Cerati, T. M. 1986. Anatomia da folha e do escapo floral de duas novas espécies de Xyris (Xyridaceae): X. dardonoi Wand. e X. tortillis Wand. Revta. bras. Bot. 9(1): 1-6.

Warming, E. 1893. Note sur la biologie et lánatomie de la feuille des Velloziacées. Overs Kgl. Danske Vid. Selsk. Kobenharn: 57-100. 